\begin{abstract}
BEIHEFTE ZUR
ZEITSCHRIFT FÜR ROMANISCHE PHILOLOGIE

BEGRÜNDET VON GUSTAV GRÖBER

FORTGEFÜHRT VON

WALTHER VON WARTBURG UND KURT BALDINGER

HERAUSGEGEBEN VON MAX PFISTER
\end{abstract}

Band 282 



\section{Spanische Sprachkultur}

Studien zur Bewertung und Pflege des öffentlichen Sprachgebrauchs im heutigen Spanien

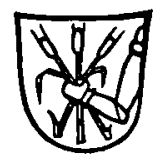

MAX NIEMEYER VERLAG TÜBINGEN 1997 
Als Habilitationsschrift auf Empfehlung der Fakultät Neuphilologie der Eberhard-KarlsUniversität Tübingen gedruckt mit Unterstützung der Deutschen Forschungsgemeinschaft

Die Deutsche Bibliothek - CIP-Einheitsaufnahme

[Zeitschrift für romanische Philologie / Beihefte]

Beihefte zur Zeitschrift für romanische Philologie. - Tübingen : Niemeyer

Früher Schriftenreihe

Reihe Beihefte zu: Zeitschrift für romanische Philologie

NE: HST

Bd. 282. Lebsanft, Franz: Spanische Sprachkultur. - 1997

\section{Lebsanfi, Franz:}

Spanische Sprachkultur : Studien zur Bewertung und Pflege des öffentlichen Sprachgebrauchs im heutigen Spanien / Franz Lebsanft. - Tübingen : Niemeyer, 1997

(Beihefte zur Zeitschrift für Romanische Philologie ; Bd. 282)

\section{ISBN 3-484-52282-8 ISSN 0084-5396}

(C) Max Niemeyer Verlag GmbH \& Co. KG, Tübingen 1997

Das Werk einschließlich aller seiner Teile ist urheberrechtlich geschützt. Jede Verwertung außerhalb der engen Grenzen des Urheberrechtsgesetzes ist ohne Zustimmung des Verlages unzulässig und strafbar. Das gilt insbesondere für Vervielfältigungen, Übersetzungen, Mikroverfilmungen und die Einspeicherung und Verarbeitung in elektronischen Systemen. Printed in Germany.

Gedruckt auf alterungsbeständigem Papier.

Satz und Druck: Gulde-Druck, Tübingen

Einband: Heinr. Koch, Tübingen 